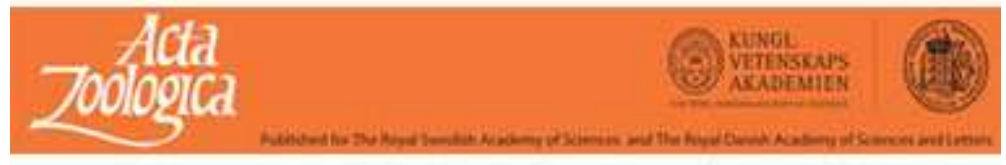

\title{
Spermiogenesis and spermatozoon ultrastructure of the dilepidid cestode Molluscotaenia crassiscolex (von Linstow, 1890), an intestinal parasite of the common shrew Sorex araneus
}

\begin{tabular}{|c|c|}
\hline Journal: & Acta Zoologica \\
\hline Manuscript ID: & AZ--10-2009-0100.R1 \\
\hline Manuscript Type: & Original Manuscript \\
\hline $\begin{array}{r}\text { Date Submitted by the } \\
\text { Author: }\end{array}$ & 10-Mar-2010 \\
\hline Complete List of Authors: & $\begin{array}{l}\text { Marigo, Adji Mama; University of Barcelona, Microbiology and } \\
\text { Parasitology } \\
\text { Bâ, Cheikh Tidiane; University Chekh Anta Diop, Animal biology } \\
\text { Miquel, Jordi; University of Barcelona, Microbiology and } \\
\text { Parasitology }\end{array}$ \\
\hline Keywords: & $\begin{array}{l}\text { Molluscotaenia crassiscolex, Dilepididae, Cyclophyllidea, Cestoda, } \\
\text { spermiogenesis, spermatozoon, ultrastructure }\end{array}$ \\
\hline
\end{tabular}

\section{S ScholaroNE \\ Manuscript Central}


Adji Mama Marigo ${ }^{1,2}$, Cheikh Tidiane Bâ ${ }^{3}$, and Jordi Miquel ${ }^{1,2}$

${ }^{1}$ Laboratori de Parasitologia, Departament de Microbiologia i Parasitologia Sanitàries, Facultat de Farmàcia, Universitat de Barcelona, Av. Joan XXIII, sn, 08028 Barcelona, Spain. ${ }^{2}$ Institut de Recerca de la Biodiversitat, Facultat de Biologia, Universitat de Barcelona, Av. Diagonal, 645, 08028 Barcelona, Spain.

${ }^{3}$ Laboratoire de Parasitologie, Département de Biologie animale, Faculté des Sciences et Techniques, Université Cheikh Anta Diop de Dakar, Dakar, Sénégal.

\title{
Keywords:
}

Molluscotaenia crassiscolex, Dilepididae, Cyclophyllidea, Cestoda, spermiogenesis, spermatozoon, ultrastructure

Running head: Sperm ultrastructure in Molluscotaenia crassiscolex

\begin{abstract}
Marigo A. M., Bâ C. T. \& Miquel J., 2009. Spermiogenesis and spermatozoon ultrastructure of the dilepidid cestode Molluscotaenia crassiscolex (von Linstow, 1890), an intestinal parasite of the common shrew Sorex araneus. - Acta Zoologica (Stockholm).

Spermiogenesis in Molluscotaenia crassiscolex begins with the formation of a differentiation zone containing two centrioles. One of the centrioles develops a flagellum directly into the cytoplasmic extension. The nucleus elongates and later migrates along the spermatid body.
\end{abstract}


During advanced stages of spermiogenesis a periaxonemal sheath appears in the spermatid. Spermiogenesis finishes with the appearance of a single helicoidal crested body at the base of the spermatid and, finally, the narrowing of the ring of arched membranes causes the detachment of the fully formed spermatozoon. The mature spermatozoon of M. crassiscolex exhibits a partially detached crested body in the anterior region of the spermatozoon, one axoneme, twisted cortical microtubules, a periaxonemal sheath, and a spiralled nucleus. The anterior spermatozoon extremity is characterized by the presence of an electron-dense apical cone and a single spiralled crested body, which is attached to the sperm cell in the anterior and posterior areas of region I, whereas in the middle area it is partially detached from the cell. This crested body is described for the first time in cestodes. The posterior extremity of the male gamete exhibits only the disorganizing axoneme. Results are discussed and compared particularly with the available ultrastructural data on dilepidids sensu lato.

Jordi Miquel, Departament de Microbiologia i Parasitologia Sanitàries, Universitat de Barcelona, Av. Joan XXIII, s/n, E-08028 Barcelona, Spain.

E-mail: jordimiquel@ub.edu

\section{Introduction}

It has now been clearly demonstrated that the ultrastructure of spermiogenesis and of the spermatozoon reveal significant characters for phylogenetic inference in parasitic Platyhelminthes (Euzet et al. 1981; Świderski 1986; Justine 1991, 1997, 1998, 2001; Bâ and Marchand 1994a, 1995; Watson and Rohde 1995; Hoberg et al. 1997; Olson et al. 2001; Świderski and Mackiewicz 2002; Levron et al. in press). There is a significant amount of information concerning the order Cyclophyllidea. Nevertheless, most of the available studies focused on the family Anoplocephalidae (see Justine 1998, 2001; Levron et al. in press). 
Within this family, subfamilies can be distinguished using spermatological data (see Levron et al. in press).

The family Dilepididae is a diverse group, which includes more than 100 genera, parasitic in birds and mammals (Bona 1994). However, spermatological data on the family Dilepididae are restricted to four species only: Angularella beema (see Yoneva et al. 2006b), Molluscotaenia crassiscolex (see Świderski and Tkach 1996), Dilepis undula (see Świderski et al. 2000) and Kowalewskiella glareola (see Świderski et al. 2002).

The taxonomy of the dilepidid cestodes sensu lato at the family level and lower groups has been controversial for a long period of time. The species of the now recognized families Dipylidiidae, Metadilepididae and Paruterinidae were previously included in the Dilepididae (Schmidt 1986). Recently, ultrastructural studies of Skrjabinoporus merops (Metadilepididae), Anonchotaenia globata and Triaenorhina rectangula (Paruterinidae), and Dipylidiidae species (see Miquel et al. 1998, 2005a; Ndiaye et al. 2003a; Yoneva et al. 2006a, 2009, in press) show differences between these groups characterised by the Type III spermiogenesis. The record of the Bâ and Marchand’s Type IV spermiogenesis in a dilepidid species (sensu stricto) further supports that Dipylidiidae, Metadilepididae and Paruterinidae should be considered distinct families in agreement with Jones et al. (1994). The latter authors sustain the recognition of the families Dilepididae (Railliet \& Henry, 1909), Metadilepididae (Spasskii, 1959), Paruterinidae (Fuhrmann, 1907) and Dipylidiidae (Stiles, 1896).

With respect to the family Gryporhynchidae (Spasskii \& Spasskaya, 1973), while being considered a subfamily of the Dilepididae by Bona (1994), Mariaux (1998) and Hoberg et al. (1999) raise it to the family level. The sole spermatological study on a gryporhynchid (Valipora mutabilis) shows a Type IV spermiogenesis (see Yoneva et al. 2008). Concerning the ultrastructural organization of the spermatozoon, dilepidids, dipylidiids and 
gryporhynchids present a Type VI spermatozoon, while metadilepidids and paruterinids present a Type VII spermatozoon (Levron et al. in press).

Although a brief unillustrated description of the mature spermatozoon of M. crassiscolex has been presented at a conference (Świderski and Tkach 1996), the present paper represents a complete ultrastructural analysis of the spermiogenesis and of the spermatozoon of this dilepidid species.

\section{Material and methods}

Naturally infected shrews (Sorex araneus) were captured in the Nature Reserve of Py (Pyrenean Mountains, France). Mature specimens of Molluscotaenia crassiscolex were collected live from the small intestine and were placed in a $0.9 \% \mathrm{NaCl}$ solution. These mature proglottids were routinely processed for transmission electron microscopic (TEM) examination; they were fixed in cold $\left(4^{\circ} \mathrm{C}\right) 2.5 \%$ glutaraldehyde in a $0.1 \mathrm{M}$ sodium cacodylate buffer at $\mathrm{pH} 7.2$ for $2 \mathrm{~h}$, rinsed in a $0.1 \mathrm{M}$ sodium cacodylate buffer at $\mathrm{pH} 7.2$, postfixed in cold $\left(4^{\circ} \mathrm{C}\right) 1 \%$ osmium tetroxide in the same buffer for $1 \mathrm{~h}$, rinsed in a $0.1 \mathrm{M}$ sodium cacodylate buffer at $\mathrm{pH}$ 7.2, dehydrated in an ethanol series and propylene oxide, and finally embedded in Spurr epoxy medium. Ultrathin sections were obtained using a ReichertJung Ultracut E ultramicrotome, placed on copper grids and double-stained with uranyl acetate and lead citrate according to Reynolds (1963). Ultrathin sections were examined using Jeol 1010 transmission electron microscope in the Scientific Services of the University of Barcelona.

The Thiéry (1967) technique was used to evidence the presence of glycogen particles. Gold grids were treated in periodic acid, thiocarbohydrazide and silver proteinate (PA-TCH-SP) as follows: 30 min in 10\% of PA, rinsed in distilled water, $24 \mathrm{hr}$ in $\mathrm{TCH}$, rinsed in acetic solutions and distilled water, $30 \mathrm{~min}$ in $1 \%$ SP in the dark, and rinsed in distilled water. 


\section{Results}

Spermiogenesis

Spermiogenesis in M. crassiscolex is described in Figures 1A-F and 2A-D. Spermiogenesis starts with the formation of a differentiation zone (Figs 1A, 2A). This is a cone-shaped area bordered by submembranous cortical microtubules containing two centrioles (Fig. 1A). Only one of the centrioles gives rise to an axoneme that grows directly into the cytoplasmic expansion (Figs 1B, D, 2B). The ring of arched membranes is present at the base of the differentiation zone (Figs 1B, C, 2B). The nucleus elongates, becomes conical and migrates along the spermatid body (Figs 1A, C, 2B, C). Initially, cortical microtubules are parallel to the spermatid axis and then they become twisted (Fig. 1B-D). Finally, a crested body appears at the anterior part of the old spermatid in the final stage of spermiogenesis (Fig. 1E, F). Additionally, an electron-dense material present in the spermatid near the ring of arched membranes forms the apical cone in the anterior extremity of the future spermatozoon (Figs $1 \mathrm{E}, \mathrm{F}, 2 \mathrm{D})$. At the end of spermiogenesis, the ring of arched membranes becomes narrower, which precedes the detachment of the spermatozoon from the residual cytoplasm (Figs 1F, 2D).

\section{Spermatozoon}

The mature spermatozoon of M. crassiscolex (Figs 3A-K, 4A-J, 5, 6I-IV) is a long filiform cell, tapered at both extremities, which lacks mitochondria. The observation of numerous longitudinal and cross-sections has enabled us to establish four regions (I-IV) characterized by distinctive ultrastructural features.

Region I (Figs 3A-J, 6I) corresponds to the anterior area of the mature spermatozoon. It exhibits an electron-dense apical cone (Fig. 3A-C) localized in the most anterior part of the 
gamete. Later, the centriole appears and it is clearly visible in cross-sections of the spermatozoon (Fig. 3D, E). The axoneme, of the 9+'1' trepaxonematan pattern, is surrounded by a thin layer of electron-lucent cytoplasm (Fig. 3F, J). The cortical microtubules constitute a submembranous electron-dense layer (Fig. 3E-G, J) and they are spiralled at an angle of $45^{\circ}$ (Fig. 3G). Externally, there is a thick helicoidal cord of electron-dense material that forms a single crested body (Fig. 3A, C-J). The positioning of the crested body is remarkable: at the anterior and posterior areas of Region I the crested body is attached to the sperm cell, being around $160 \mathrm{~nm}$ thick (Fig. 3A, C-G, I). However, in the intermediate part the crested body is partially detached from the cell and its thickness increases to $330 \mathrm{~nm}$ (Fig. 3H, J).

Region II (Figs 3I, K, 4A-D, 5, 6II) is characterized by the appearance of a periaxonemal sheath and electron-dense granules (Figs 3K, 4A-D). In the anterior areas of this region the cortical microtubules form a submembranous continuous layer and both periaxonemal sheath and electron-dense granules are absent (Fig. 3I, K). Posterior areas of Region II are characterized by the discontinuity of cortical microtubules in the submembranous layer and by the presence of both electron-dense granules and periaxonemal sheath (Figs 3K, 4A-D). These electron-dense granules are located between the periaxonemal sheath and the submembranous layer of cortical microtubules and may constitute either a thin (Fig. 4B) or a thicker layer (Figs 3K, 4C). The test of Thiéry (1967) shows the absence of contrast demonstrating the non-glycogenic nature of this electron-dense granular material (Fig. 5).

Region III (Figs 4D-G, I, 6III) presents the nucleus coiled around the axoneme in a helicoidal form. In cross-sections, the nucleus is horseshoe-shaped or almost annular (Fig. 4F, G). This region is also characterized by the lack of both electron-dense granules and periaxonemal sheath. Cortical microtubules stop their course at the end of this region (Fig. 4G, I).

Region IV (Figs 4H, I, 6IV) corresponds to the posterior spermatozoon extremity, which includes only the axoneme surrounded by the plasma membrane (Fig. 4H). Towards the end 


\section{Discussion}

Spermiogenesis

Within the order Cyclophyllidea, spermiogenesis is divided in two types (Bâ and Marchand 1995): Type III is characterized by the formation of a single flagellum that grows parallel to the cytoplasmic protrusion followed by the proximodistal fusion whereas Type IV describes the growth of the axoneme directly into the cytoplasmic protrusion. Type III spermiogenesis occurs in some Anoplocephalidae, and also in Nematotaeniidae, Davaineidae, Dipylidiidae, Metadilepidae, Paruterinidae, Catenotaeniidae and Taeniidae. On the other hand, Type IV spermiogenesis is present in some Anoplocephalidae, in Dilepididae and in Hymenolepidae (see Justine 1998, 2001; Levron et al. in press). To date, the ultrastructural analysis of spermiogenesis in Angularella beema constituted the only available data on dilepidids (Yoneva et al. 2006b). The present study showed that the spermiogenesis process in $M$. crassiscolex, as in A. beema, also follows the Type IV of Bâ and Marchand (1995). Among cyclophyllideans, mesocestoidids constitute the only exception, presenting a Type II spermiogenesis, which is characterised by the flagellar rotation of a single flagellum followed by its proximodistal fusion with a cytoplasmic extension, and by the presence of both intercentriolar body and striated rootlets in the zone of differentiation (see Miquel et al. 1999, 2007a). According to the original description of Bâ and Marchand (1995), the cyclophyllidean types III and IV lack both intercentriolar body and striated rootlets in the zone of differentiation. However, posterior studies have shown certain particularities. This is the case of the well-developed striated rootlets present in Joyeuxiella species (Dipylidiidae) 
(see Ndiaye et al. 2003a) and the vestigial striated rootlets which include thin, spiralled and filamentous striated rootlets, found in the zone of differentiation of the anoplocephalids Anoplocephaloides dentata, Gallegoides arfaai, Moniezia expansa and Mosgovoyia ctenoides (see Miquel and Marchand 1998, Li et al. 2003, Miquel et al. 2005b, Eira et al. 2006), the dipylidiid Dipylidium caninum (see Miquel et al. 1998, 2005a), the metadilepidid Skrjabinoporus merops (see Yoneva et al. 2006a), the paruterinids Triaenorhina rectangula and Anonchotaenia globata (see Yoneva et al. 2009, in press), and the taeniid Taenia taeniaeformis (see Miquel et al. 2009).

Bâ and Marchand (1995) describe the presence of an electron-dense material, the centriolar adjunct, associated with centrioles in the zone of differentiation in the type IV spermiogenesis. This structure has been observed in the anoplocephalid cyclophyllideans Thysaniezia ovilla (Bâ et al. 1991), Gallegoides arfaai (Miquel et al. 2005b) and Mosgovoyia ctenoides (Eira et al. 2006). Other anoplocephalids (Anoplocephaloides dentata, Aporina delafondi and Moniezia expansa -see Bâ and Marchand 1994b, Miquel and Marchand 1998, Li et al. 2003), the dilepidid A. beema (Yoneva et al. 2006b), the gryporhynchid V. mutabilis (Yoneva et al. 2008) and the hymenolepidid Rodentolepis nana (Bâ and Marchand 1992) also follow a type IV spermiogenesis but they lack the centriolar adjunct as occurs in the case of M. crassiscolex spermiogenesis. Other centriole-associated structures, the intercentriolardense material and the electron-dense material, are described in anoplocephalid Sudarikovina taterae (Bâ et al. 2000) and in the hymenolepidid Rodentolepis microstoma (Bâ and Marchand 1998), respectively.

According to several authors (see Ndiaye et al. 2003a, Miquel et al. 2005a, in press) the process of cytoplasmic condensation and posterior twisting of cortical microtubules during spermiogenesis probably plays an important role in the origin of the periaxonemal sheath present in the mature spermatozoon of cyclophyllideans. This has been clearly described in 


\section{Spermatozoon}

According to Levron et al. (in press) there are seven types of spermatozoa in the Eucestoda. The latter authors consider three different types of spermatozoa for cyclophyllideans (types $\mathrm{V}$ through VII). Type $\mathrm{V}$ is characteristic of hymenolepidids, nematotaeniids and some anoplocephalids. Type VII is found in the davaineids, metadilepidids, paruterinids, taeniids and certain anoplocephalids, and also in tetrabothriideans. The ultrastructural organization of the mature spermatozoon of $M$. crassiscolex corresponds to the type VI, which is characterized by the presence of one axoneme, spiralled cortical microtubules, spiralled nucleus, crested body and periaxonemal sheath. This pattern is present in the Catenotaeniidae, Dilepididae, Dipylidiidae, Gryporhynchidae and in the Anoplocephalidae genera Mathevotaenia and Stilesia (see Levron et al. in press). With respect to the family Mesocestoididae, studies on M. litteratus and M. lineatus (see Miquel et al. 1999, 2007a) have revealed plesiomorphic characters (as in the case of spermiogenesis) and the ultrastructural organization of their spermatozoa corresponds to Type IV, which is also present in lecanicephalideans and in the phyllobothriid tetraphyllideans.

The generally accepted sperm characters interpreted as synapomorphies for the Eucestoda are the absence of mitochondria in the mature sperm (Justine 1991) and the presence of one or 
more helical crested bodies (Bâ and Marchand 1995). The validity of the latter is questionable because their absence in the sperm cell of caryophyllideans, spathebothriideans and trypanorhynchs (see Justine 2001 and Levron et al. in press). The synapomorphies for the cyclophyllidean + tetrabothriidean include the presence of twisted peripheral microtubules and the presence of periaxonemal sheath (Justine 2001). However, the validity of the latter character as a synapomorphy may be impeded by the anoplocephalid cyclophyllideans whose spermatozoa lack periaxonemal sheath (see Yoneva et al. 2006b).

The present results on $M$. crassiscolex are in agreement with the previous ultrastructural studies on spermatozoa of dilepidid cestodes (Świderski et al. 2000, 2002; Yoneva et al. 2006b - see Table I). The mature spermatozoon of $M$. crassiscolex exhibits a single crested body that marks the anterior extremity of the gamete (Bâ et al. 1991). Among cyclophyllideans, the number of crested bodies varies from 1 to 12 (see Bâ and Marchand 1995; Justine 1998; Bâ et al. 2000). A single helical crested body is present in the cyclophyllidean families Dilepididae (Świderski et al. 2000, 2002; Yoneva 2006b), Dipylidiidae (Miquel and Marchand 1997, Ndiaye et al. 2003a, Miquel et al. 2005a), Mesocestoididae (Miquel et al. 1999, 2007a), Metadilepididae (Yoneva et al. 2006a), Nematotaeniidae (Mokhtar-Maamouri and Azzouz-Draoui 1990), Paruterinidae (Yoneva et al. 2009, in press) and Taeniidae (Miquel et al. 2000, Ndiaye et al. 2003b, Willms et al. 2004), whereas Catenotaeniidae and Davaineidae are characterised by the presence of two crested bodies (Miquel et al. 1997, in press; Bâ and Marchand 1994a, c; Hidalgo et al. 2000; Bâ et al. 2005a, b). The spermatozoa of the Hymenolepididae possess multiple (6-12) crested bodies (Bâ and Marchand 1992, 1993, 1996, 1998; Miquel et al. 2007b), while in the Anoplocephalidae species the number of crested bodies varies from 1 to 7 (Bâ and Marchand 1994b, Bâ et al. 2000, Miquel et al. 2004, Eira et al. 2006). The particular morphology of the crested body observed in $M$. crassiscolex is reported for the first time in a cestode. In fact, 
while the anterior and posterior areas of region I show a crested body adjacent to the sperm cell, in the middle area the crested body is partially detached from the cell.

Although the transverse intracytoplasmic walls are usually present in the spermatozoon of species that also exhibit a periaxonemal sheath (see Justine 1998), the mature spermatozoon of $M$. crassiscolex lacks intracytoplasmic walls while presenting a periaxonemal sheath. In fact, as describe Levron et al. (in press), transverse intracytoplasmic walls and periaxonemal sheath consist of characters that they are not associated in all the studied species. Thus, according to these authors, among the cyclophyllidean types of spermatozoon, the type VI presents only periaxonemal sheath and the type VII exhibits both periaxonemal sheath and transverse intracytoplasmic walls. The periaxonemal sheath characterizing the posterior part of region II of the spermatozoon of $M$. crassiscolex is present in all dilepidid, dipylidiid, gryporhynchid, metadilepidid and paruterinid cestodes that have been studied to date (see Table I). Among these families, only the metadilepidid $S$. merops and the paruterinids $T$. rectangula and A. globata (Yoneva et al. 2006a, 2009, in press) exhibit both intracytoplasmic walls and periaxonemal sheath in agreement with the above mentioned statement by Justine (1998).

The ultrastructure of the posterior region of the spermatozoon in M. crassiscolex shows only the axoneme surrounded by the plasma membrane. The cortical microtubules stop their course at the end of the nuclear region and thus the distal spermatozoon extremity is characterized by the absence of peripheral microtubules and the posterior disappearance of the central core unit followed by the gradual disintegration of doublets. This schema is in agreement with those found in the previously studied dilepidids $D$. undula (Świderski et al. 2000) and A. beema (Yoneva et al. 2006b), in the dipylidiid genus Joyeuxiella (Ndiaye et al. 2003a), in the gryporhynchid $V$. mutabilis (Yoneva et al. 2008), in the metadilepidid $S$. 
merops (Yoneva et al. 2006a) and in the paruterinids T. rectangula (Yoneva et al. 2009) and A. globata (Yoneva et al. in press).

\section{Concluding remarks}

Type IV spermiogenesis is the characteristic pattern of dilepidids as revealed by the comparative analysis of the available spermatological data. During spermiogenesis, a rootlike structure is absent in all the studied dilepidids. Concerning the ultrastructural organization of the mature spermatozoon, dilepidids present a type VI spermatozoon, which is characterized by the presence of (1) a single axoneme, (2) spiralled cortical microtubules and nucleus, (3) a periaxonemal sheath and (4) a single crested body. Although these characteristics clearly differentiate dilepidids from dipylidiids, metadilepidids and paruterinids they do not differentiate dilepidids from gryporhynchids, which present similar spermiogenesis and spermatozoa ultrastructural characters.

\section{Acknowledgement}

Authors wish to thank the staff of the Nature Reserve of Py (Claude Guisset and David Morichon, in particular) (Pyrenean Mountains, France) for their hospitality and valuable help in the fieldwork. We also thank "Serveis Científics i Tècnics" of the University of Barcelona for their support in the preparation of samples. Study partially supported by the Spanish Projects 2009SGR-403 and CGL2009-07759/BOS. Adji Mama Marigo benefits from a MAEC-AECID doctoral grant (2009-10, nº 0000448124).

\section{References}

Bâ, A., Bâ, C. T. and Marchand, B. 2000. Ultrastructure of spermiogenesis and the spermatozoon of Sudarikovina taterae (Cestoda, Cyclophyllidea, Anoplocephalidae) 
intestinal parasite of Tatera gambiana (Rodentia, Gerbillidae). - Journal of Submicroscopic Cytology and Pathology 32: 137-144.

Bâ, C. T., Bâ, A. and Marchand, B. 2005a. Ultrastructure of the spermatozoon of Raillietina (Raillietina) baeri (Cyclophyllidea, Davaineidae) an intestinal parasite of the multimammate rat, Mastomys huberti (Rodentia, Muridae). - Parasitology Research 97: 173-178.

Bâ, C. T., Bâ, A. and Marchand, B. 2005b. Ultrastructure of the spermatozoon of Paroniella reynoldsae (Cyclophyllidea, Davaineidae) an intestinal parasite of Corvus albus (Aves, Corvidae). - Acta Parasitologica 50: 208-214.

Bâ, C. T. and Marchand, B. 1992. Reinvestigation of the ultrastructure of spermiogenesis and the spermatozoon of Hymenolepis nana (Cestoda, Cyclophyllidea), parasite of the small intestine of Rattus rattus. - Molecular Reproduction and Development 33: 39-45.

Bâ, C. T. and Marchand, B. 1993. Ultrastructure of the Retinometra serrata spermatozoon (Cestoda) intestinal parasite of turtle-doves in Senegal. - Journal of Submicroscopic Cytology and Pathology 25: 233-238.

Bâ, C. T. and Marchand, B. 1994a. Similitude ultrastructurale des spermatozoïdes de quelques Cyclophyllidea. - Parasite 1: 51-55.

Bâ, C. T. and Marchand, B. 1994b. Ultrastructure of spermiogenesis and the spermatozoon of Aporina delafondi (Cyclophyllidea, Anoplocephalidae) intestinal parasite of turtle doves in Senegal. - International Journal for Parasitology 24: 225-235. 


\begin{abstract}
Bâ, C. T. and Marchand, B. 1994c. Ultrastructure of spermiogenesis and the spermatozoon of Raillietina (Raillietina) tunetensis (Cyclophyllidea, Davaineidae) intestinal parasite of turtle doves in Senegal. - International Journal for Parasitology 24: 237-248.
\end{abstract}

Bâ, C. T. and Marchand, B. 1995. Spermiogenesis, spermatozoa and phyletic affinities in the Cestoda. - Mémoires du Muséum National d'Histoire Naturelle 166: 87-95.

Bâ, C. T. and Marchand, B. 1996. Ultrastructure of the spermatozoon of Hymenolepis straminea (Cyclophyllidea, Hymenolepididae) intestinal parasite of Arvicanthis niloticus in Senegal. - Invertebrate Reproduction and Development 29: 243-247.

Bâ, C. T. and Marchand, B. 1998. Ultrastructure of spermiogenesis and the spermatozoon of Vampirolepis microstoma (Cestoda, Hymenolepididae), intestinal parasite of Rattus rattus. Microscopy Research and Technique 42: 218-225.

Bâ, C. T., Marchand, B. and Mattei, X. 1991. Demonstration of the orientation of the cestodes spermatozoon illustrated by the ultrastructural study of spermiogenesis and the spermatozoon of a Cyclophyllidea: Thysaniezia ovilla, Rivolta, 1874. - Journal of Submicroscopic Cytology and Pathology 23: 605-612.

Bona, F. V. 1994. Family Dilepididae Railliet \& Henry, 1999. In: Keys to the cestode parasites of vertebrates (Eds L. F. Khalil, A. Jones and R. A. Bray). CAB International, Wallingford, 443-554. 
Eira, C., Miquel, J., Vingada, J. and Torres, J. 2006. Spermiogenesis and spermatozoon ultrastructure of the cestode Mosgovoyia ctenoides (Cyclophyllidea: Anoplocephalidae), an intestinal parasite of Oryctolagus cuniculus (Lagomorpha: Leporidae). - Journal of Parasitology 92: 708-718.

Euzet, L., Świderski, Z. and Mokhtar-Maamouri, F. 1981. Ultrastructure comparée du spermatozoïde des Cestodes. Relations avec la phylogenèse. - Annales de Parasitologie (Paris) 56: 247-259.

Hidalgo, C., Miquel, J., Torres, J. and Marchand, B. 2000. Ultrastructural study of spermiogenesis and the spermatozoon in Catenotaenia pusilla, an intestinal parasite of Mus musculus. - Journal of Helminthology 74: 73-81.

Hoberg, E. P., Jones, A., and Bray, R. A. 1999. Phylogenetic analysis among the families of the Cyclophyllidea (Eucestoda) based on comparative morphology, with new hypotheses for co-evolution in vertebrates. - Systematic Parasitology 42: 51-73.

Hoberg, E. P., Mariaux, J., Justine, J.-L., Brooks, D. R. and Weekes, P. J. 1997. Phylogeny of the orders of the Eucestoda (Cercomeromorphae) based on comparative morphology: historical perspectives and a new working hypothesis. - Journal of Parasitology 83: 11281147.

Jones, A., Bray, R. A. and Khalil, L. F. 1994. Order Cyclophyllidea van Beneden in Braun, 1990. In: Keys to the cestode parasites of vertebrates (Eds. L. F. Khalil, A. Jones and R. A. Bray). CAB International, Wallingford, 305-307. 
Justine, J.-L. 1991. Phylogeny of parasitic Platyhelminthes: a critical study of synapomorphies proposed on the basis of the ultrastructure of spermiogenesis and spermatozoa. - Canadian Journal of Zoology 69: 1421-1440.

Justine J.-L. 1997. La classification générale des Plathelminthes parasites: changements récents et utilisation des caractères ultrastructuraux, en particulier des spermatozoïdes. Bulletin de la Société Française de Zoologie 122: 226-277.

Justine, J.-L. 1998. Spermatozoa as phylogenetic characters for the Eucestoda. - Journal of Parasitology 84: 385-408.

Justine, J.-L. 2001. Spermatozoa as phylogenetic characters for the Platyhelminthes. In: Interrelationships of the Platyhelminthes (Eds. D. T. J. Littlewood and R. A. Bray R.A.). Taylor and Francis, London, 231-238,

Levron, C., Miquel, J., Oros, M. and Scholz, T. in press. Spermatozoa of tapeworms (Platyhelminthes, Eucestoda): advances in ultrastructural and phylogenetic studies. Biological Reviews.

Li, H.-Y., Brennan, J. P. and Halton, D. W. 2003. Spermatogenesis, spermiogenesis and spermatozoon in the cestode (Moniezia expansa) (Cyclophyllidea, Anoplocephalidae). - Acta Zoologica Sinica 49: 370-379. 
Mariaux, J. 1998. A molecular phylogeny of the Eucestoda. - Journal of Parasitology 84: 114-124.

Miquel, J., Bâ, C. T. and Marchand, B. 1997. Ultrastructure of the spermatozoon of Skrjabinotaenia lobata (Cyclophyllidea, Catenotaeniidae), intestinal parasite of Apodemus sylvaticus (Rodentia, Muridae). - Journal of Submicroscopic Cytology and Pathology 29: 521-526.

Miquel, J., Bâ, C. T. and Marchand, B. 1998. Ultrastructure of spermiogenesis of Dipylidium caninum (Cestoda, Cyclophyllidea, Dipylidiidae), an intestinal parasite of Canis familiaris. International Journal for Parasitology 28: 1453-1458.

Miquel, J., Eira, C., Świderski, Z. and Conn, D. B. 2007a. Mesocestoides lineatus (Goeze, 1782) (Mesocestoididae): new data on sperm ultrastructure. - Journal of Parasitology 93: $545-552$.

Miquel, J., Feliu, C. and Marchand, B. 1999. Ultrastructure of spermiogenesis and the spermatozoon of Mesocestoides litteratus (Cestoda, Mesocestoididae). - International Journal for Parasitology 29: 499-510.

Miquel, J., Hidalgo, C., Feliu, C. and Marchand, B. 2000. Sperm ultrastructure of Taenia mustelae (Cestoda, Taeniidae), an intestinal parasite of the weasel, Mustela nivalis (Carnivora). - Invertebrate Reproduction and Development 38: 43-51.

Miquel, J. and Marchand, B. 1997. Ultrastructure of the spermatozoon of Dipylidium 
caninum (Cestoda, Cyclophyllidea, Dilepididae), an intestinal parasite of Canis familiaris. Parasitology Research 83: 349-355.

Miquel, J. and Marchand, B. 1998. Ultrastructure of spermiogenesis and the spermatozoon of Anoplocephaloides dentata (Cestoda, Cyclophyllidea, Anoplocephalidae), an intestinal parasite of Arvicolidae rodents. - Journal of Parasitology 84: 1128-1136.

Miquel, J., Ndiaye, P. I. and Feliu, C. 2007b. Crest-like bodies in the spermatozoon of Hymenolepididae cestodes from Iberian rodents. - Revista Ibérica de Parasitología 67: 2733.

Miquel, J., Świderski, Z., Foronda, P., Torres, J. and Feliu, C. 2009. Ultrastructure of spermatogenesis of Taenia taeniaeformis (Batsch, 1786) (Cestoda, Cyclophyllidea, Taeniidae) and comparison of spermatological characters in the family Taeniidae Ludwig, 1886. - Acta Parasitologica 54: 230-243.

Miquel, J., Świderski, Z. and Marchand, B. 2005a. Spermatological characters in the Dipylidiidae Stiles, 1896 (Cestoda, Cyclophyllidea). - Acta Parasitologica 50: 65-73.

Miquel, J., Świderski, Z., Młocicki, D., Eira, C. and Marchand, B. 2005b. Spermatogenesis in the anoplocephalid cestode Gallegoides arfaai (Mobedi et Ghadirian, 1977) Tenora et MasComa, 1978. - Acta Parasitologica 50: 132-144.

Miquel, J., Świderski, Z., Młocicki, D. and Marchand, B. 2004. Ultrastructure of the spermatozoon of the anoplocephalid cestode Gallegoides arfaai (Mobedi and Ghadirian, 
1977) Tenora and Mas-Coma, 1978, an intestinal parasite of the wood mouse (Apodemus sylvaticus Linnaeus, 1758). - Parasitology Research 94: 460-467.

Miquel, J., Torres, J., Foronda, P. and Feliu, C. in press. Spermiogenesis and spermatozoon ultrastructure of the davaineid cestode Raillietina micracantha (Fuhrmann, 1909). - Acta Zoologica (Stockholm) 91.

Mokhtar-Maamouri, F. and Azzouz-Draoui, N. 1990. Spermiogenèse et ultrastructure du spermatozoïde de Nematotaenia chantalae Dollfus, 1957 (Cestoda, Cyclophyllidea, Nematotaeniidae). - Annales de Parasitologie Humaine et Comparée 65: 221-228.

Ndiaye, P. I., Agostini, S., Miquel, J. and Marchand, B. 2003a. Ultrastructure of spermiogenesis and the spermatozoon in the genus Joyeuxiella Fuhrmann, 1935 (Cestoda, Cyclophyllidea, Dipylidiidae): comparative analysis of J. echinorhynchoides (Sonsino, 1889) and J. pasqualei (Diamare, 1893). - Parasitology Research 91: 175-186.

Ndiaye, P. I., Miquel, J. and Marchand, B. 2003b. Ultrastructure of spermiogenesis and spermatozoa of Taenia parva Baer, 1926 (Cestoda, Cyclophyllidea, Taeniidae), a parasite of the common genet (Genetta genetta). - Parasitology Research 89: 34-43.

Olson, P. D., Littlewood, D. T. J., Bray, R. A. and Mariaux, J. 2001. Interrelationships and Evolution of the Tapeworms (Platyhelminthes: Cestoda). - Molecular Phylogenetics and Evolution 19: 443-467. 
Reynolds, E. S. 1963. The use of lead citrate at high $\mathrm{pH}$ as an electron-opaque stain in electron microscopy. - Journal of Cell Biology 17: 208-212.

Schmidt, G. D. 1986. CRC handbook of tapeworm identification. CRC Press, Boca Raton.

Świderski, Z. 1986. Three types of spermiogenesis in cestodes. - Proceedings of the XIth International Congress of Electron Microscopy, Kyoto, Japan: 2959-2960.

Świderski, Z. and Mackiewicz, J. S. 2002. Ultrastructure of spermatogenesis and spermatozoa of the caryophyllidean cestode Glaridacris catostomi Cooper, 1920. - Acta Parasitologica 47: 83-104.

Świderski, Z., Salamatin, R. V. and Kornyushin, V. V. 2002. Ultrastructure of the spermatozoon of the dilepidide cestode Kowalewskiella glareola (Burt, 1940) Lopez-Neyra, 1952. - Proceedings of the 12th Conference of Ukrainian Society of Parasitologists, Sevastopoul, Crimea: 132.

Świderski, Z., Salamatin, R. V. and Tkach, V. V. 2000. Electron microscopial study of spermatozoa of the cestode Dilepis undula (Cyclophyllidea, Dilepididae). - Vestnik Zoologii 34: 3-7.

Świderski, Z. and Tkach, V. V. 1996. Ultrastructure of mature spermatozoon in dilepidid cestode Molluscotaenia crassiscolex (Linstow, 1890). - Parassitologia 38: 97. 
Thiéry, J. P. 1967. Mise en évidence des polysaccharides sur coupes fines en microscopie électronique. - Journal of Microscopy 6: 987-1018.

Watson, N. A. and Rohde, K. 1995. Sperm and spermiogenesis of the "Turbellaria” and implications for the phylogeny of the Phylum Platyhelminthes. - Mémoires du Muséum National d'Histoire Naturelle 166: 37-54.

Willms, K., Robert, L., Jiménez, J. A., Everhart, M. and Kuhn, R. E. 2004. Ultrastructure of spermiogenesis and the spermatozoon in Taenia crassiceps strobilae WFU strain (Cestoda, Cyclophyllidea, Taeniidae) from golden hamsters. - Parasitology Research 93: 262-267.

Yoneva, A., Georgieva, K., Mizinska, Y., Georgiev, B. B. and Stoitsova, S. R. 2006a. Ultrastructure of spermiogenesis and mature spermatozoon of Skrjabinoporus merops (Cyclophyllidea, Metadilepididae). - Acta Parasitologica 51: 200-208.

Yoneva, A., Georgieva, K., Mizinska, Y., Nikolov, P. N., Georgiev, B. B. and Stoitsova, S. R. in press. Ultrastructure of spermiogenesis and mature spermatozoon of Anonchotaenia globata (von Linstow, 1879) (Cestoda, Cyclophyllidea, Paruterinidae). - Acta Zoologica (Stockholm).

Yoneva, A., Georgieva, K., Nikolov, P. N., Mizinska, Y., Georgiev, B. B. and Stoitsova, S. R. 2009. Ultrastructure of spermiogenesis and mature spermatozoon of Triaenorhina rectangula (Cestoda: Cyclophyllidea: Paruterinidae). - Folia Parasitologica 56: 275-283. 
Yoneva, A., Miquel, J., Świderski, Z., Georgieva, K., Mizinska, Y. and Georgiev, B. B. 2006b. Ultrastructure of spermiogenesis and mature spermatozoon of Angularella beema (Clerc, 1906) (Cestoda, Cyclophyllidea, Dilepididae). - Acta Parasitologica 51: 264-272.

Yoneva, A., Świderski, Z., Georgieva, K., Nikolov, P. N., Mizinska, Y. and Georgiev, B. B. 2008. Spermiogenesis and sperm ultrastructure of Valipora mutabilis Linton, 1927 (Cestoda, Cyclophyllidea, Gryporhynchidae). - Parasitology Research 103: 1397-1405.

\section{Figure captions}

Fig. 1 - Spermiogenesis of Molluscotaenia crassiscolex. - A. Zone of differentiation showing two centrioles (C) and the nucleus (N). Bar $=0.5 \mu \mathrm{m}$. - B. Longitudinal section of a zone of differentiation showing the elongation of the axoneme $(A x)$ in the cytoplasmic extension (CE) bordered by the cortical microtubules (CM) and delimited by the arched membrane (AM). Bar $=0.5 \mu \mathrm{m} .-$ C. Longitudinal section of spermatids showing the migrating nucleus $(\mathrm{N})$ into the cytoplasmic extension. AM, arched membranes. Bar $=0.5 \mu \mathrm{m}$. - D. Cross-sections of spermatids before the twisting of cortical microtubules (CM). G, granules. Bar $=0.3 \mu \mathrm{m}$. - E. Longitudinal section of a zone of differentiation showing the formation of the crested body (CB). AM, arched membranes. Bar $=0.5 \mu \mathrm{m}$. F. Final stage of the spermiogenesis showing the detachment of the spermatid after the formation of the apical cone (AC). CB, crested body. Bar $=0.5 \mu \mathrm{m}$.

Fig. 2(A-D) - Schematic drawing showing the main stages of spermiogenesis of Molluscotaenia crassiscolex. AC, apical cone; AM, arched membranes; C, centriole; 
CB, crested bodies; CE, cytoplasmic extension; CM, cortical microtubules; N, nucleus; RC, residual cytoplasm.

Fig. 3 - Spermatozoon of Molluscotaenia crassiscolex. - A. Longitudinal section of Region I showing the apical cone, the anterior spermatozoon extremity (ASE) and the crested body $(\mathrm{CB})$. Bar $=0.5 \mu \mathrm{m}$. - B. Cross-section of Region I showing the electron-dense apical cone (AC). Bar $=0.3 \mu \mathrm{m}$. - C-D. Cross-sections of posterior areas of the apical cone (AC) in Region I showing the presence of one crested body (CB) and the beginning of centriole $(\mathrm{C})$. Bars $=0.3 \mu \mathrm{m}$. - E. Cross-section of Region I the level of the centriole. $\mathrm{CB}$, crested body; $\mathrm{CM}$, cortical microtubules. Bar $=0.3 \mu \mathrm{m}$. $-\mathbf{F}$. Cross-section of anterior areas of Region I showing the axoneme. CB, crested body; CM, cortical microtubules. Bar $=0.3 \mu \mathrm{m}$. - G. Longitudinal section of Region I showing the anterior axonemal extremity marked by the presence of the centriole (C). CB, crested body; CM, cortical microtubules. Bar $=0.5 \mu \mathrm{m}$. - H. Longitudinal section of Region I showing the detached crested body (CB) in the median part of this region. Bar $=0.5 \mu \mathrm{m}$. - I. Longitudinal section showing the transition area between Region I (RI) and Region II (RII). CB, crested body. Bar $=0.5 \mu \mathrm{m} .-\mathbf{J}$. Cross-section showing the detached crested body (CB) in the middle area of Region I. CM, cortical microtubules. Bar $=0.3 \mu \mathrm{m}$. $-\mathbf{K}$. Cross-section of Region II showing the periaxonemal sheath (PS), the electron-dense granules (G) and the cortical microtubules $(\mathrm{CM})$. Bar $=0.3 \mu \mathrm{m}$.

Fig. 4 - Spermatozoon of Molluscotaenia crassicolex. - A. Longitudinal section of Region II showing the periaxonemal sheath (PS) surrounding the axoneme (Ax), and electrondense granules (G). CM, cortical microtubules. Bar $=0.5 \mu \mathrm{m}$. - B-C. Cross-sections 
of Region II showing the periaxonemal sheath (PS) and the different aspect of electron-dense granules (G). CM, cortical microtubules. Bars $=0.3 \mu \mathrm{m}$. D. Longitudinal section of the transition zone between Region II (RII) and Region III (RIII) (nuclear region). G, electron-dense granules; N, nucleus; PS, periaxonemal sheath. Bar $=0.5 \mu \mathrm{m}$. - E. Longitudinal section of the nuclear region. N, nucleus. Bar $=0.5 \mu \mathrm{m} .-\mathbf{F}$. Cross-section of the nuclear region showing the nucleus $(\mathrm{N})$ in a horse-shoe shape and the twisted cortical microtubules $(\mathrm{CM})$. Bar $=0.3 \mu \mathrm{m}$. $-\mathbf{G}$. Cross-section of the nuclear region near the end of the nucleus showing the posterior extremity of cortical microtubules $(\mathrm{CM})$. Bar $=0.3 \mu \mathrm{m}$. - H. Cross-section of Region IV at the level of the posterior end showing the axoneme surrounded by the plasma membrane. Bar $=0.3 \mu \mathrm{m}$. - I. Cross-section of Region IV showing the disorganization of the axoneme forming doublets (D). Bar $=0.3 \mu \mathrm{m}$. $-\mathbf{J}$. Longitudinal section of the transition zone of Regions III (RIII) and IV (RIV). Note that the cortical microtubules (CM) stop at the end of Region III and that Region IV presents a reduced length. The arrowhead indicates the disappearance of the central core. Ax, axoneme; D, doublets; N, nucleus; PSE, posterior spermatozoon extremity. $\operatorname{Bar}=0.5 \mu \mathrm{m}$.

Fig. 5 - Several cross-sections showing the non-glycogenic nature of electron-dense granules (G) evidenced by the application of Thiéry staining. N, nucleus. Bar $=0.5 \mu \mathrm{m}$.

Fig. 6(I-IV) - Schematic drawing showing the ultrastructural organization of the mature spermatozoon of Molluscotaenia crassiscolex. AC, apical cone; ASE, anterior spermatozoon extremity; Ax, axoneme; C, centriole; CB, crested body; CM, cortical 
microtubules; G, electron-dense granules; N, nucleus; PM, plasma membrane; PS, periaxonemal sheath; PSE, posterior spermatozoon extremity. 
Family and species

Spermatozoon

$\begin{array}{lllllll}\text { Type } & \text { PR } & \text { PF } & \text { IB } & \text { RLS Type AC }\end{array}$ thickn.

\section{DILEPIDIDAE}

Angularella beema

Dilepis undula

Kowalewskiella glareola

Molluscotaenia crassiscolex

IV

-

\section{DIPYLIDIIDAE}

Dipylidium caninum

Joyeuxiella echinorhynchoides

Joyeuxiella pasqualei

GRYPORHYNCHIDAE

Valipora mutabilis

METADILEPIDIDAE

Skrjabinoporus merops

PARUTERINIDAE

Anonchotaenia globata

Triaenorhina rectangula

$\begin{array}{llllll}\text { III } & <90^{\circ} & + & - & \text { VSR } & \text { VII } \\ \text { III } & <90^{\circ} & + & - & \text { VSR } & \text { VII }\end{array}$

$35-45^{\circ}+$

twisted

$160-33045^{\circ}$

$150 \quad 40^{\circ}$

$150 \quad 40$

75

$40^{\circ}$
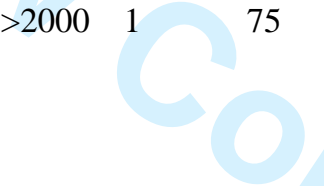

)
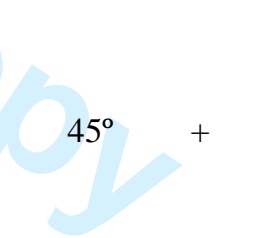

1

$1 \quad 75$

$35^{\circ}$

$40^{\circ}$
References

CM PS G IW 


\section{Page 27 of 33}

\section{Acta Zoologica}

AC: apical cone (length), CB: crested body (number and thickness), CM: angle of cortical microtubules, FR: flagellar rotation, G: electron-dense granules, IB: intercentriolar body, IW: intracytoplasmic walls, PF: proximodistal fusion, PS: periaxonemal sheath, RLS: root-like structures, SR: striated rootlets, VSR: vestigial striated rootlets, +/-: presence/absence of character, ?: data required to be confirmed.

Spermiogenesis types are considered according Bâ and Marchand (1995).

Spermatozoa types are considered according Levron et al. (in press).

All measurements are given in $\mathrm{nm}$. 

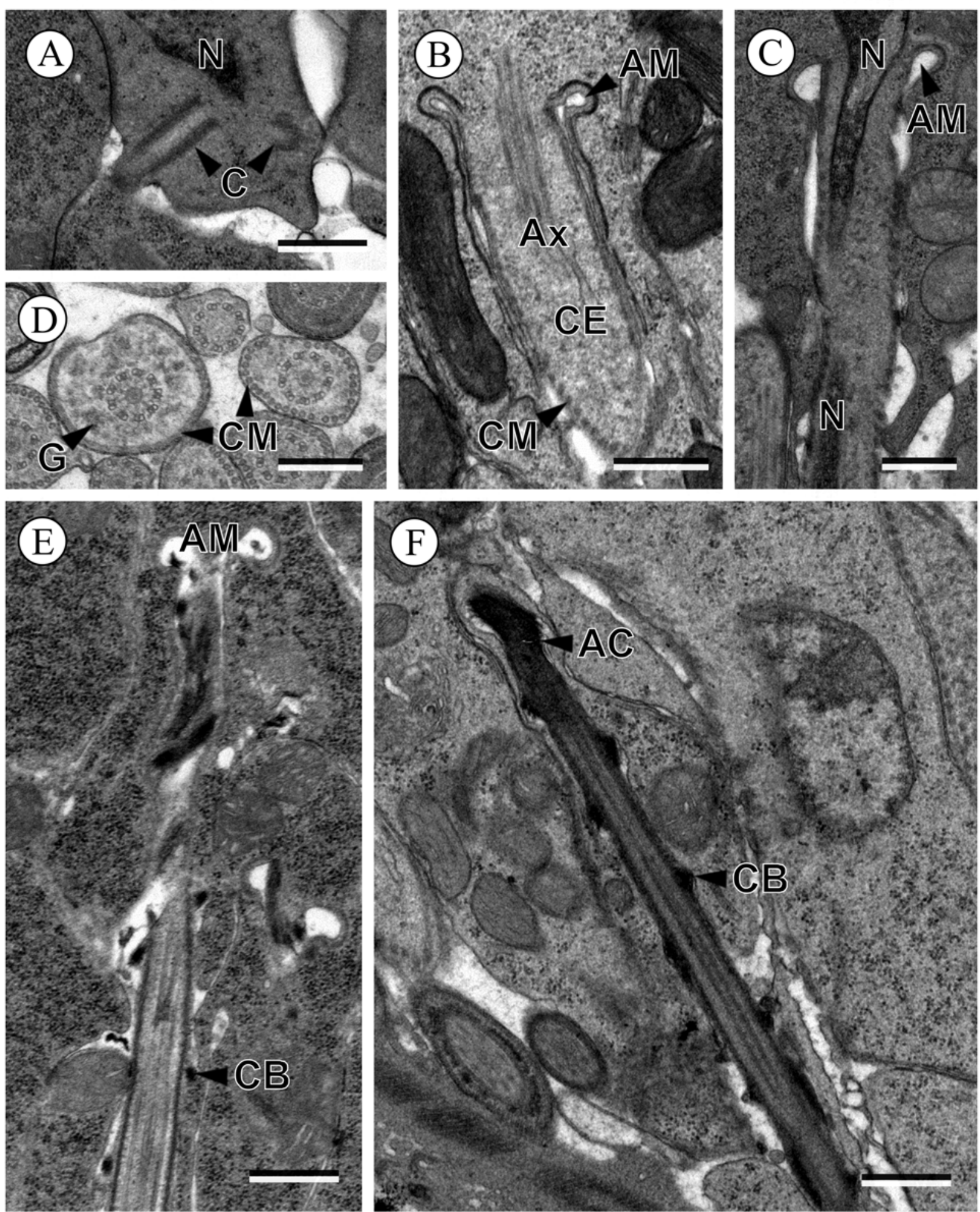
(A)

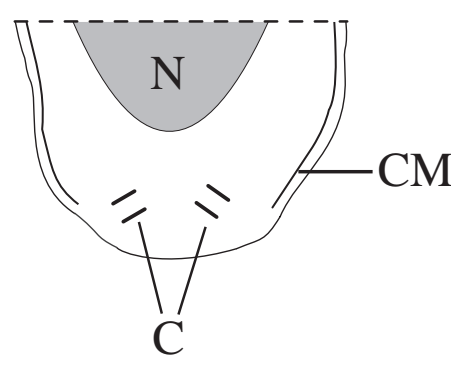

(B)

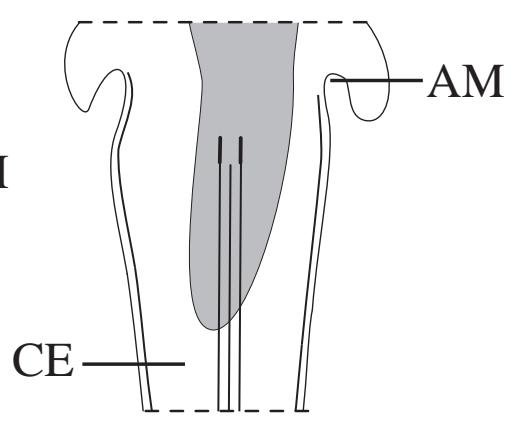

(C)

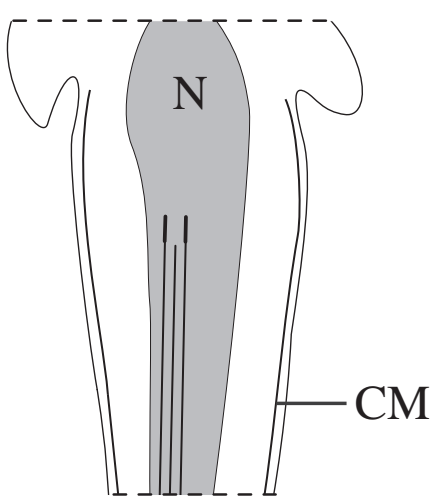

(D)

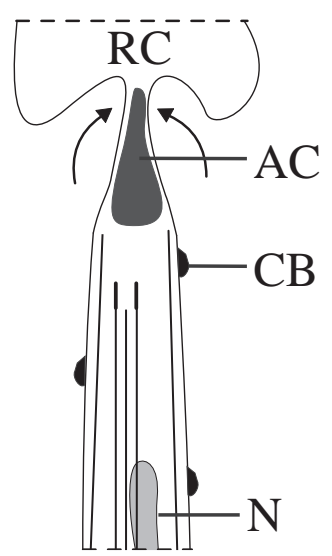



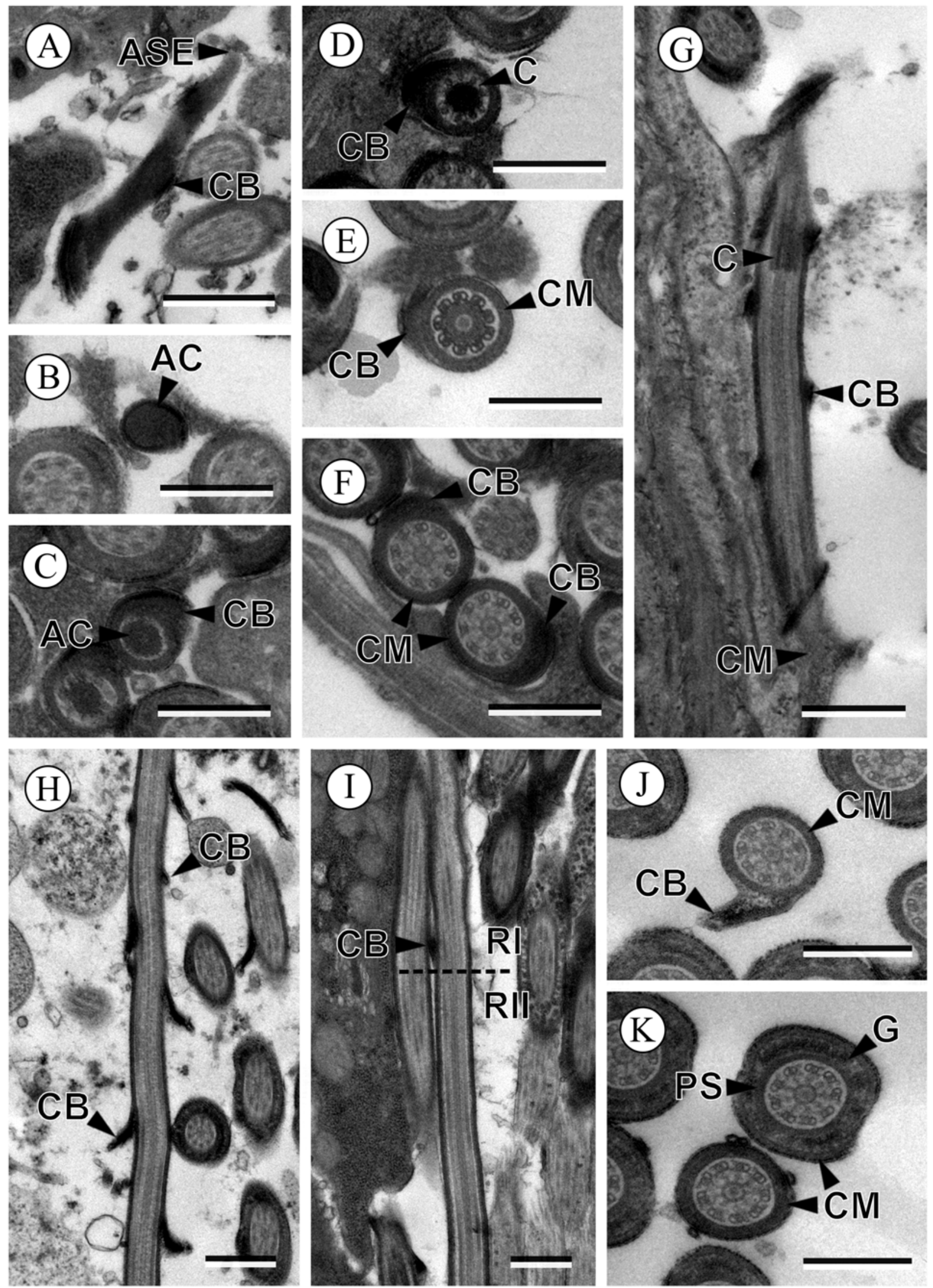

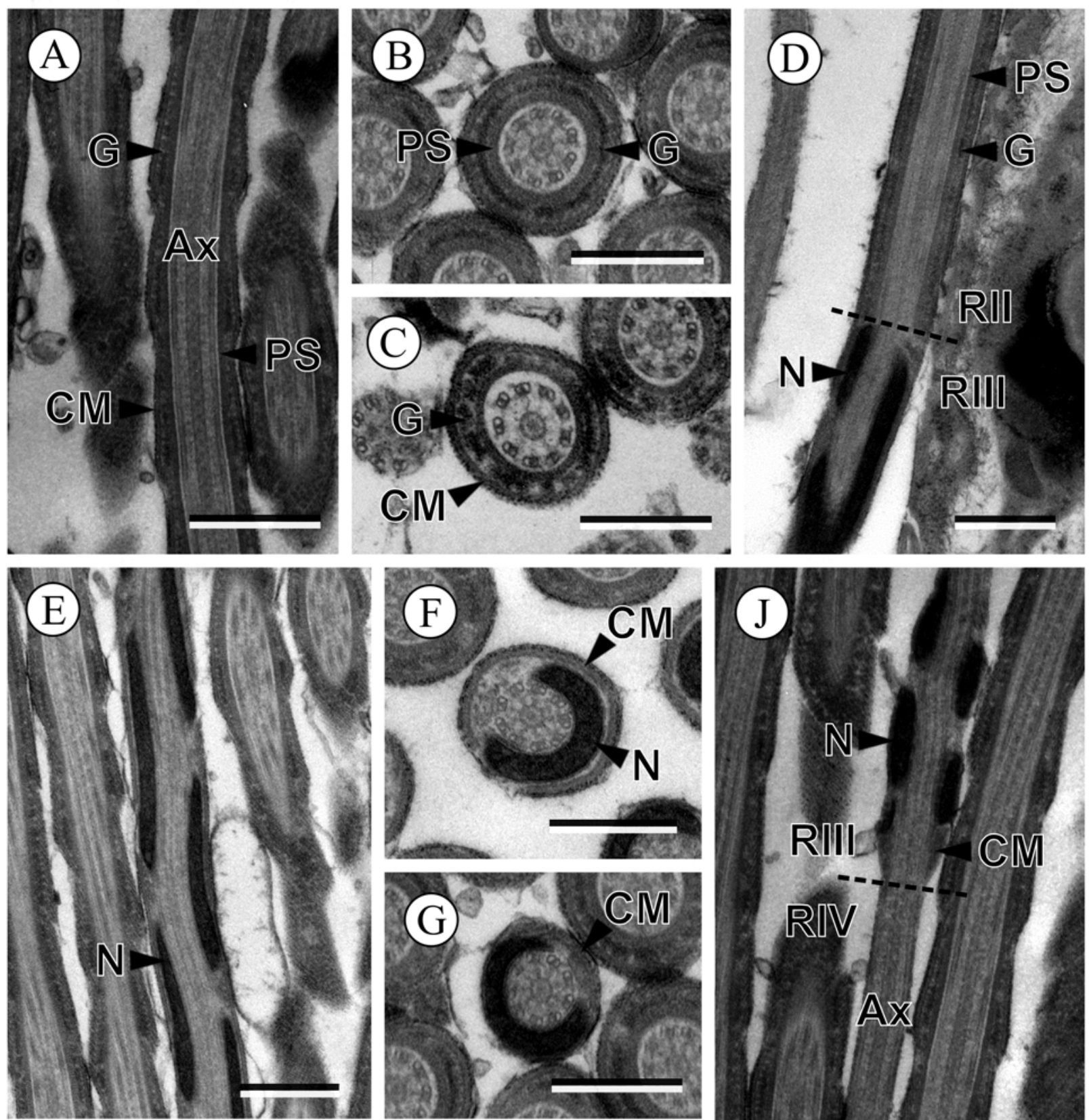

32

34

35

36

37

38

39

40

41

42

43

44

45

46

47

48

49

50

51

52

53

54

55

56

57
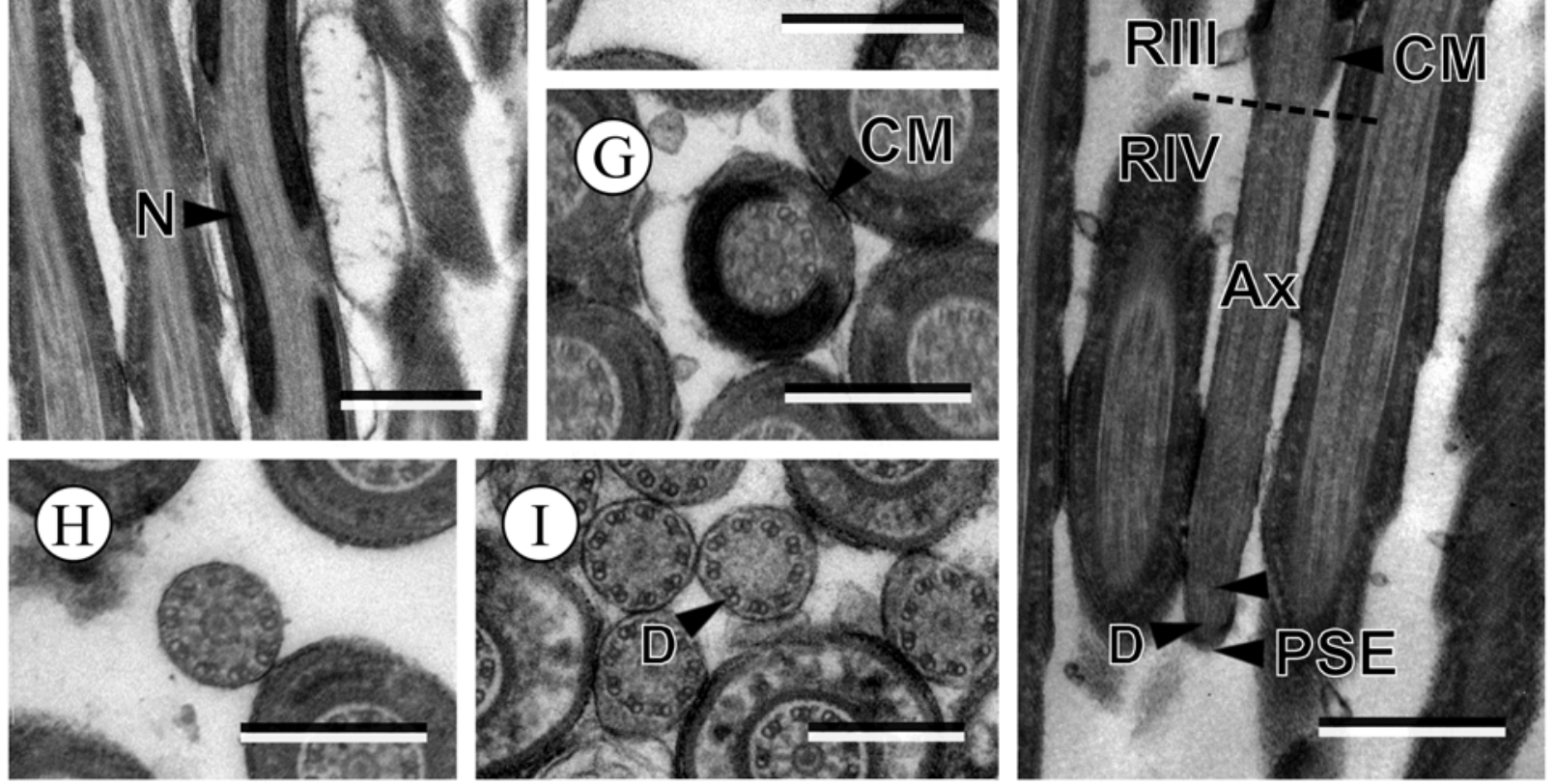


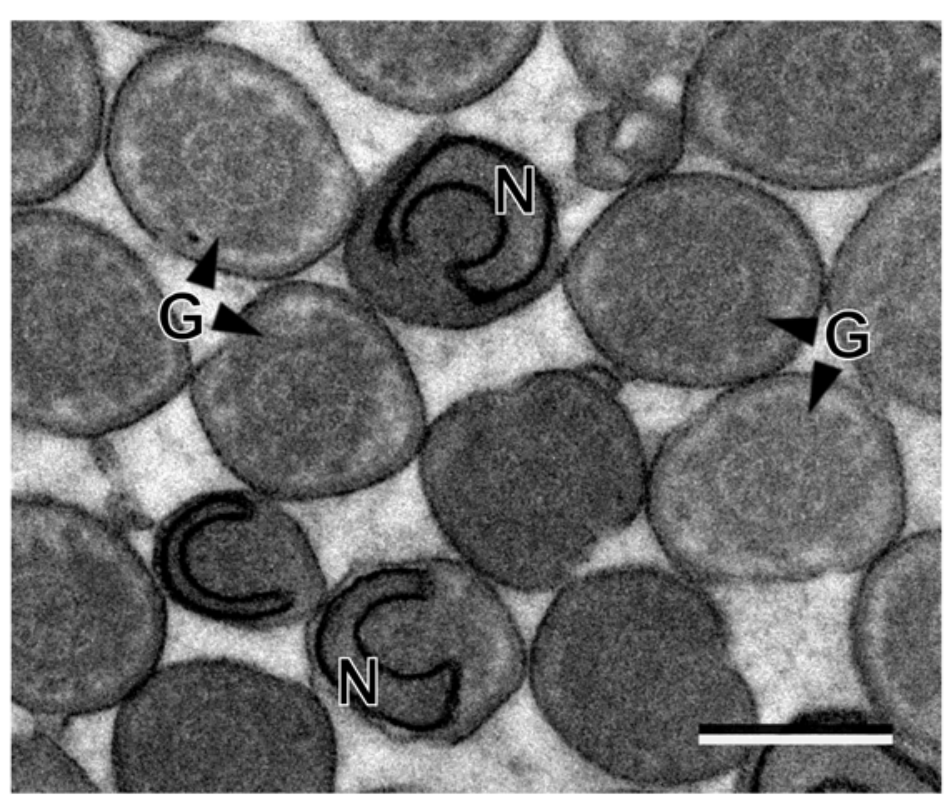




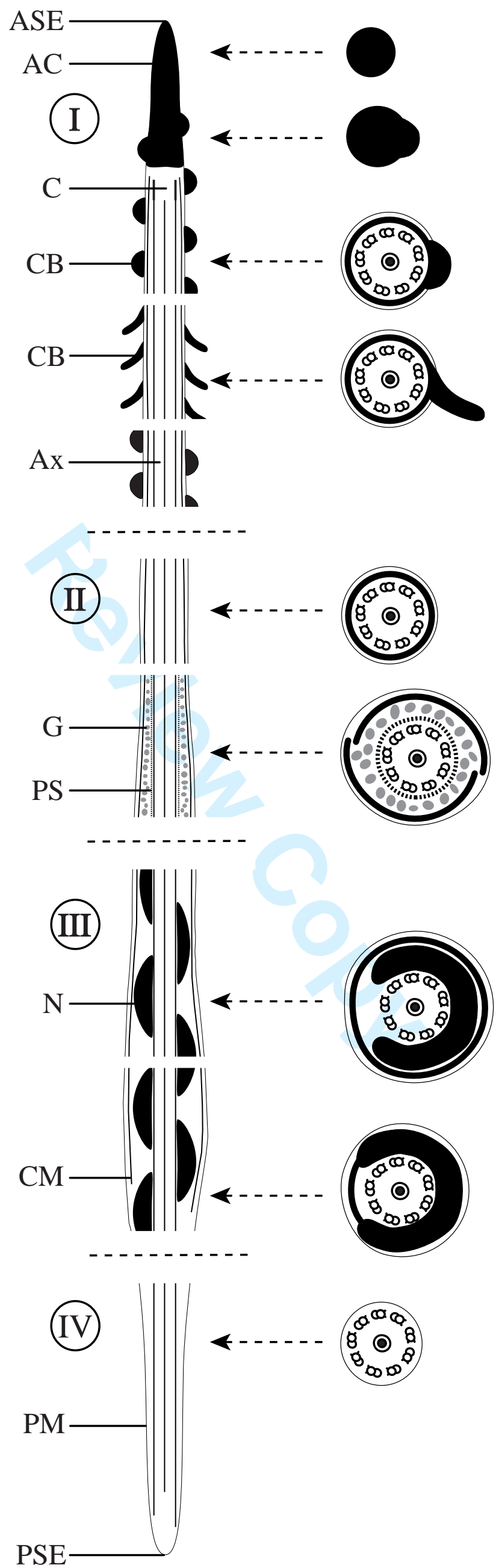

